\title{
Europa del este y el tercer mundo*
}

\author{
Jan Patula \\ UAM-IZTAPALAPA
}

C on el hundimiento del socialismo real en Europa del este y la desaparición de facto de la llamada "comunidad socialista" quedaron modificados los principales parámetros de las relaciones internacionales. Incluso perdió su significado histórico la división del mundo acuñada por el economista y demógra. fo francés A. Sauvy: el primer mundo (los países capitalistas altamente desarrollados), el segundo mundo (los países autodenominados socialistas con la URSS a la cabeza) y el tercer mundo (los países restantes, principalmente ex colonias).

Obviamente no desaparecieron los países que hace poco pertenecieron al "campo socialista", tampoco cambió

* Este artículo fue redactado antes de ta desaparición de la URSS. radicalmente la realidad en los países en vía del desarrollo en lo que respecta a la pobreza endémica, los frenos estructurales en el crecimiento económico, las condiciones lacerantes de educación, salud, vivienda, etc., ni el círculo vicioso de dependencia de tecnologías y capitales extranjeros.

En el presente ensayo nos proponemos exáminar el giro en las relaciones entre Europa oriental y los países del tercer mundo a partir del derrumbe del socialismo real, así como las perspectivas para el futuro. De antemano, queremos advertir que se trata de constelaciones absolutamente nuevas; mejor dicho de las que están en el proceso de incubación en que las normas y los principios viejos perdieron toda su vigencia y los nuevos están por establecerse, por crearse. En esa coyuntura, tan frágil e inestable, lo que po- 
demos ofrecer es plantear ciertas alternativas, considerándolas abiertas y sujetas a precisiones, bajo ciertas condiciones.

A título de antecedentes hay que constatar una simbiosis, al menos ideológica, entre la causa de los países colonizados o recientemente liberados, por un lado, y la Unión Soviética y posteriormente lo que se autodenominó "la comunidad socialista". En opinión de A. Dueñas Pulido, ex embajador de México en la URSS, desde que la revolución socialista se hizo gobierno, se autonombró líder del mundo "atrasado" y colonial en su lucha por la independencia nacional y modelo para su desarrollo económicosocial. Los dirigentes bolcheviques re. lacionaron así la supervivencia y la suerte del movimiento anticolonial y la superación del atraso económico con el devenir del "proyecto bolchevique". ${ }^{1}$ En los escritos de los dirigentes políticos, los discursos oficiales y los materiales de los congresos del partido comunista de la Unión Soviética y otros países "hermanos" se puede confirmar la apreciación de A. Dueñas Pulido con algunos matices o enfoques particulares, conforme a la coyuntura internacional y/o prioridades políticas de la URSS. Cabe subrayar que las relaciones ideológico-políticas, económicas, hasta militares de la URSS y otros países del bloque soviético con el tercer mundo se han caracterizado por modificaciones bastante radicales, a tal grado que muchos estudiosos de la materia las dividen por etapas y periodos bien definidos. ${ }^{2}$

\footnotetext{
1 Dueñas, "Visión", 1989, p. 685.

2 Hough, Struggle, 1986, caps. 3 y 4 .
}

A partir de la década de los años 50 , el tercer mundo se convirtió en la arena privilegiada de la rivalidad soviético-norteamericana. Ambas superpotencias que al mismo tiempo encabezaron dos bloques político-militares se valieron de todos los recursos, incluyendo la intervención militar o el apoyo armamentista a unos grupos rebeldes. El ampliar la zona de influencia a costa de su adversario fue considerado uno de los objetivos principales de las dos superpotencias. ${ }^{3}$ No abordamos aquí -porque no es nuestro objetivo- la configuración de fuerzas en el interior de cada uno de los países tercermundistas en disputa, que propiciaron la confrontación de EUA y la URSS para aprovecharse de la oportu. nidad histórica.

Los otros países del bloque soviético participaron en esa rivalidad por el tercer mundo. Las tareas y las obligaciones concretas de cada Estado eurooriental estaban al respecto designadas y coordinadas en el seno de dos organizaciones de integración políticomilitar y económica: el Pacto de Varsovia y el came (Comecon), respectivamente, siendo la RDA y Checoslovaquia, países de mayor desarrollo económico, los más involucrados en todo tipo de "ayuda" a los Estados tercermundistas. ${ }^{4}$ Ésta se extendía desde la asistencia tecnológica, junto con la presencia de los expertos y técnicos, hasta la entrega de armas y el entrenamiento de los cuadros guerrilleros, pasando por una vasta red de penetración ideológica, de espionaje y contraespionaje.

3 Katz, "Soviet", 1986, pp. 329 y ss.

'Albright, "USSR", 1989, pp. 65-67. 
Resumiendo la interpretación oficial de los vínculos entre la "comunidad socialista" y los países del tercer mundo en los últimos tiempos de Brejnev, cabe resaltar los siguientes argumentos:

1. La mera existencia del socialismo real ejerce una poderosa influencia sobre el "proceso revolucionario mundial", por el simple hecho de haber creado "una vasta zona del género humano que ofrece la garantía de que la paz, la libertad y el progreso social triunfarán".

2. Los paises socialistas otorgan un "apoyo por fiador", de naturaleza política, económica e ideológica, a "las fuerzas revolucionarias y a su lucha contra las tendencias antidemocráticas, imperialistas y neocolonialistas". De este modo, "este apoyo reduce la presión de las fuerzas imperialistas y reaccionarias sobre el movimiento revolucionario y limita las posibilidades de ellas para exportar la contrarrevolución hacia los países donde tienen lugar los cambios revolucionarios".

3. El tercer camino a través del cual el socialismo real influye en el "proceso revolucionario mundial" es por medio del "gran impacto revolucionador sobre la mente de los participantes en ese proceso" y que podría sintetizarse en la expresión: "mediante la fuerza el ejemplo". El autor distingue dos acepciones del término. En el primero, en el sentido estrecho, se trata de "armar las fuerzas revolucio. narias con el conocimiento de los medios con que había sido creado un nuevo régimen social y había consolidado su victoria en los países del socia- lismo realmente existente". En el sentido amplio del término, hay que entender la "fuerza del ejemplo" en la demostración del "crecimiento efectivo social y económico a la par con justas relaciones sociales" de los últimos. ${ }^{5}$

A pesar de que el texto está redactado en un lenguaje lleno de grandilocuencia y algunos párrafos incluso en el lenguaje de Esopo, nos da la idea de una vinculación muy estrecha que existió entre Europa central y el llamado "movimiento revolucionario mundial" en los países del tercer mundo. Cabe insistir en "armar a los revolucionarios con el conocimiento de", lo que traducido a la lengua cotidiana significó, nada más y nada menos, adiestrar ideológica, política y militarmente a aquellos agrupamientos rebeldes que correspondían a la visión euro-oriental del "movimiento revolucionario mundial". Hay que añadir que se trató de un escrito autorizado del jefe de un departamento en el Instituto Económico del Sistema Socialista Mundial de la Academia Soviética de las Ciencias.

Por razones de espacio no podemos extendernos en presentar el deslizamiento paulatino de los estudiosos en las relaciones del mundo del socialismo real con los países del tercer mundo, ${ }^{6}$ hacia otra percepción de las prioridades y enfoques analíticos de éstas. En cambio, queremos señalar la

5 Reproducido en Soviet Foreign Policy, cap. $v$, "The USSR and the third world", seleccion de documentos hecha por Current Digest of the Soctet Press, $2^{2}$ edición, 1986, p. 125.

6 Hough, Struggle, 1986, caps. 3 y 4. 
ruptura que representó el ascenso de Gorbachov al poder en 1985 y el inicio de la perestroika con respecto a la política internacional soviética hacia el tercer mundo.

En esencia, el "nuevo pensamiento", como suele calificarse el giro en la política exterior de la URSS, consistió en abandonar la confrontación en pos de la cooperación a escala global, en sus relaciones con Estados Unidos y su actitud hacia el tercer mundo. Según el mismo Gorbachov: "Estoy convencido de que la raza humana ha entrado en una etapa en la que todos dependemos de los demás. Ninguna nación o país debe ser considerado en forma aislada de los otros, ni mucho menos enfrentado a otro" ${ }^{7}$

Conforme con esas premisas, la Unión Soviética bajo Gorbachov optó en los hechos por resolver pacíficamente los conflictos regionales, presos anteriormente de la rivalidad esteoeste, en Asia, África y América Latina y retiró unilateralmente en febrero de 1989 sus tropas de Afganistán, el "Vietnam" para los soviéticos desde 1979. Pero lo crucial para el cambio del nuevo orden internacional era el permitir a los pueblos de Europa central recuperar su plena soberanía, de hacer decidir a ellos mismos su destino. ${ }^{8} \mathrm{Al}$ abandonar la "doctrina Brejnev" sobre la soberanía limitada de los países so. cialistas, éstos decidieron deshacerse de los regímenes del socialismo real

${ }^{7}$ Gorbachov, Petestroika, 1990, p. 221.

8 Insisto en que el retiro del apoyo sovietico a los regímenes de Europa central ha sido decisivo para su caída; más ampliamente sobre las bases ontologicas del socialismo real en mi artículo "Ontología" (en prensa). en cuestión de un par de semanas o días en el memorable año de 1989. Estos son hechos ampliamente conocidos como para insistir en ellos.

¿Qué efectos inmediatos tuvo el hundimiento del socialismo real en Europa central sobre los países del tercer mundo? Creemos que sería erróneo responder tajantemente que desaparecieron los tres niveles de la simbiosis entre socialismo real y tercer mundo, esbozados anteriormente, estableciéndose en su lugar un vacío. $\mathrm{Ni}$ puede tampoco afirmarse que con la desaparición del "sistema socialista mundial" se esfumó por completo y para todo el mundo el ideal del socialismo cultivado en la URSS y otros paises de Europa central, así como propagado en los países del tercer mundo. Antonio Navarro Wolf, el líder del grupo político colombiano M-19, hasta hace poco un movimiento guerrillero, refiriéndose a otros movimientos guerrilleros en su país constató:

Sí creo que de verdad están buscando un futuro, que no es el futuro. Sí creo que dentro de las FARC y del ELN están buscando el socialismo que ya pas 6 a la historia, que no tiene futuro. Esas motivaciones ideológicas se quedaron en el pasado, y ellos no se han dado cuenta y se niegan a aceptarlo.?

En el mejor de los casos, se podría sostener la tesis de que el ideal del socialismo real haya perdido su fuerza de atracción para mucha gente en el tercer mundo. Pero difieren las con-

9 Entrevista con Navarro Wolf, "Peligro", 1991 , p. 31. 
clusiones que ésta saca del derrumbe del socialismo real. Nos dedicaremos ahora a ellas, haciendo advertencia de que no son unívocas.

En el plano ideológico se encuentran personas que sostienen la tesis de que el hundimiento del socialismo real en Europa central representa una oportunidad histórica para la renovación del socialismo, una vez que éste quedó liberado de las lacras burocráticas, de las tergiversaciones sistemáticas en nombre del socialismo, pero negando su esencia: la liberalización del hombre y las sociedades de cualquier tipo de opresión. Así pues, desaparecido y desacreditado el modelo del socialismo soviético, se abren ahora las perspectivas para construir un socialismo "verdadero", "humanista", que concilie las exigencias de la libertad individual, social y nacional con las de la justicia en diferentes niveles. La necesidad de un tal socialismo se hace más imperiosa, ya que persisten y se agravan los problemas del orden económico, social, cultural, internacional, etcétera. Rechazando el modelo del socialismo burocrático, esas personas preconizan la lucha por un socialismo democrático a escala mundial, el único capaz de resolver los problemas de la humanidad. En México representan esa postura Adolfo Sánchez Vázquez, Pablo González Casanova y los animadores de la revista Socialismo bajo la redacción de Eduardo Montes, para mencionar solamente a los portavoces más destacados intelectualmente.

En el plano político, el hundimiento del socialismo real y el fin de la guerra fría significó el cese del apoyo a los regímenes autoritarios y represivos en Asia, África y América Latina. En boca de C. Pabon, militante del Movimiento Socialista Popular de Puerto Rico,

el apoyo del bloque soviético a sus aliados impuso la consolidación de las elites del poder, políticamente autoritarias y militares. También ha contribuido a la represión de los movimientos de la oposición democrática, así como ha envuelto a esas sociedades en una creciente militarización. ${ }^{10}$

El autor cuestiona la pretensión oficialista de una ayuda desinteresada y la promoción de la justicia social. E. Hutchful, originario de Ghana y profesor de Ciencias Políticas en la Universidad de Toronto, valoriza igualmente la terminación de la guerra fría en el continente africano, lo que ha significado

la militarización de los conflictos continentales y nacionales que se prolongaron interminablemente porque ninguna de las partes había tenido o se le había permitido poseer una ventaja decisiva militarmente; la aparición de los regímenes débiles política y administrativamente, que sin embargo adquirieron una capacidad militar desproporcional, regímenes tan diversos como Zaire y Etiopía, sostenidos por los patrones foráneos, los que rehusaron buscar una necesaria acomodación con sus poblaciones nacionales. ${ }^{11}$

¿Cómo entonces explicarse el estallido del conflicto en el golfo Pérsico

10 Pabon, "Implications", 1990, p. 25.

11 Hutchfull, Peace, 1990, p. 21. 


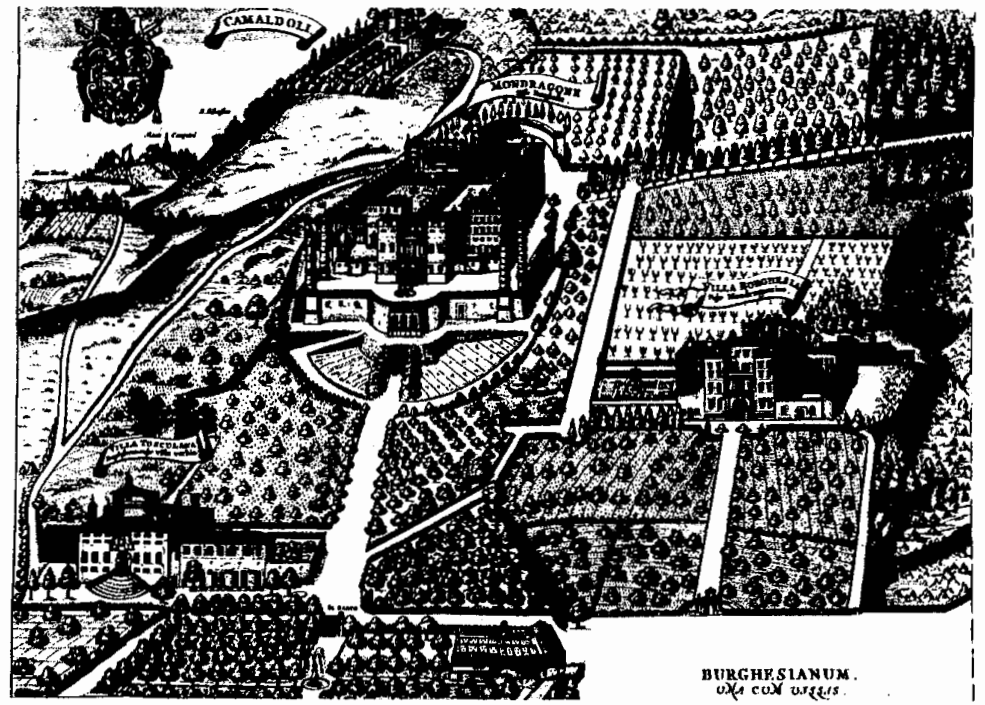

en 1990 y su culminación que todos conocemos en 1991?

En primer lugar, se hizo manifiesto el enorme cúmulo de armas de todo tipo, de las más sofisticadas y perniciosas a la vez, como las armas químicas y bacteriológicas, en manos del Iraq de Hussein. Es menester hacer hincapié sobre la más diversa procedencia de esos armamentos; de la URSS y otros países del bloque soviético hasta Brasil y Argentina y pasando casi por todos los Estados euro-occidentales. Ello no era otra cosa que el fruto de la confrontación este-oeste, de la carrera armamentista y la persecución de las hegemonías globales y regionales.

En segundo lugar, la anexión de Kuwait por Iraq se encontró con el rechazo generalizado de la comunidad internacional, como nunca antes se había visto. En esta ocasión, el Consejo de Seguridad de la ONU elaboró y presentó el ultimátum para el retiro de las tropas iraquíes y cuando éste no se cumplió, autorizó el uso de la fuerza. Éste fue un elemento completamente nuevo, el resultado del fin de la guerra fría, ya que ni la URSS ni China, miembros permanentes del Consejo de Seguridad, impusieron el veto. El desenlace militar ya era el problema técnicologístico llevado a cabo por el alto mando estadunidense, con lo que se reafirmó la supremacía político-militar de este país. La Unión Soviética, por su parte, intentó mediar en el conflicto a última hora para evitar la conflagración regional, pero sin éxito. La maquinaria de guerra ya estaba en plena marcha y Gorbachov, pese a las críticas de ciertos sectores militares de su 
país, decidió resignarse en lugar de recurrir a la amenaza de fuerza. Indudablemente prevalecieron los problemas internos, sobre todo la necesidad de una reforma económica a fondo y la búsqueda de ayuda occidental.

Se ha llamado al conflicto en el golfo Pérsico la "primera guerra del siglo XXI". ${ }^{12}$ ¿Con razón? Si consideramos que el año de 1989 cierra el siglo $\mathrm{xx}$, entendido como la "centuria de la guerra total" -para utilizar la afortunada designación de Raymond Aron- entonces, el conflicto en el golfo Pérsico responde perfectamente, desde el punto de vista cronológico a tal nombre. Pero vista la guerra política e históricamente, surgen ciertas interrogantes y dudas, la primera y a nuestro parecer la más importante, se refiere a que esa guerra puso de relieve la herencia bien viva de la confrontación, el comercio de armas y el hegemonialismo globál y regional que con la proclamación del fin de la guerra fría parecían pertenecer al pasado. Una ilusión falsa. El segundo elemento, digno de tomarse en cuenta, es que muchísimos conflictos regionales, étnicos, sociales tienen su origen propio, es decir, las causas profundas provienen de la configuración de fuerzas internas y la rivalidad soviéticonorteamericana sólo la explotó para beneficios propios. Esta aseveración se comprueba en el caso de Iraq-Kuwait, al igual que en tantísimos conflictos en otras regiones del planeta. Volveremos a abordar esta temática más adelante al hablar de las perspectivas para el futuro, a raiz del cambio de las relacio-

12 Juan María Alponte, El Nacional, 17 enero 1991, pp. 1, 4. nes de Europa del este con el tercer mundo.

Desde el punto de vista económico, el efecto inmediato que tuvo el hundimiento del socialismo real sobre los países tercermundistas no es fácil de sintetizar en un par de líneas. Por un lado, hay que tomar en cuenta que la participación de los países euro-orientales, incluyendo a la URSS, en ayuda, inversiones directas y comercio internacional hacia el tercer mundo era, en términos generales, sumamente baja. ${ }^{13}$ Por otro lado, la situación de los países socialistas y tercermundistas a la vez, como Corea del Norte, Vietnam y Mongolia, tuvieron un sistema económico autárquico, con escasa vinculación con el exterior y, por ende, el cambio de los regímenes en Europa central no les afectó grandemente. Había que anotar el caso de Vietnam que descle hace más de un lustro inició una reestructuración económica tanto en los aspectos administrativos como en la liberalización del comercio, pequeña manufactura y agricultura privados. Un grupo de los países con orientación socialista, como oficialmente se denominó a Estados con una vinculación muy estrecha con el bloque soviético, optó por cambiar el rumbo al evidenciarse la quiebra económica en sus propios países, debido en el fondo a la adopción del modelo soviético de la economía. Según el ya citado $C$. Pabon, el efecto de imitar el modelo económico soviético se tradujo en

13 Sobre este tema en una amplia perspectiva histórica, vease: Valkanier, "Treinta", 1988, pp. 720-753. 
la economía de mando por el partidoEstado, que ha fracasado miserablemente en cumplir el bienestar de amplias mayorías del pueblo, pero que ha tenido la capacidad de infligir irreparables daños ecológicos. En suma, la ayuda del bloque soviético ha contribuido a la consolidación de esa caricatura conocida con el nombre de "el socialismo del tercer mundo". ${ }^{14}$

La apreciación -muy tajante- de C. Pabon contrasta con la valorización del conocido ensayista y escritor latinoamericano, Eduardo Galeano, quien dijo:

Es necesario entender que desde el punto de vista de América Latina y el llamado tercer mundo, el difunto bloque soviético tuvo al menos una virtud fundamental: no se había enriquecido en despojar a los pobres, tampoco había participado en la rapiña por medio del mercado capitalista internacional. Por el contrario, había ayudado a implantar la justicia en Cuba, Nicaragua y muchos otros países. Presagio que en el futuro no muy lejano, eso se va a recordar con nostalgia. ${ }^{15}$

Al examinar los efectos inmediatos del hundimiento del socialismo real en Europa central hay que detenerse un momento en el caso de Cuba. Ese país caribeño, autoglorificado desde principios de los años 60 (el rompimiento de las relaciones con Estados Unidos y el bloqueo y la política de aislamiento de Cuba por parte del coloso del norte) el "primer país libre

14 Pabon, "Implications", 1990, p. 25.

15 Excélsior, 16 de octubre de 1990, p. 2. en el continente americano", ha sido la piedra de toque de la guerra fría no sólo en toda América Latina, sino en el globo terráqueo. Huelga recordar que en 1962 el mundo entero estuvo al borde de la guerra atómica, a raiz del conflicto de los misiles, es decir, la instalación en la isla de los cohetes con ojivas nucleares soviéticas. El régimen de Fidel Castro fue constantemente acusado de "exportar la revolución" por doquier, de adiestrar y armar a los insurgentes y a la guerrilla en numerosos países de América Latina, de mandar tropas militares y asesores a varios países de África; en breve, de servir de instrumento a la política expansionista de la URSS y su bloque. ${ }^{16}$

Como era de esperarse, el cambio de los regímenes en Europa central ha significado la terminación de las relaciones privilegiadas que esos países han mantenido con Cuba. Se trató de un resultado natural y consecuente con la puesta en marcha de nuevos principios organizativos: la democracia pluripartidista y la economía de mercado. Sintomático para el giro en las relaciones de Europa central con Cuba fue el voto recriminatorio de la violación de los derechos humanos en la isla caribeña ante la Comisión de los Derechos Humanos de la ONU por parte de los representantes de los nuevos gobiernos centroeuropeos a principios de 1990. Poco después vino la llamada crisis de las embajadas en la cual estaba envuelta la representación diplomática checoslovaca, por haber abierto sus puertas a los refugiados cubanos. La reacción de las autorida-

${ }^{16}$ Staar, Soviet, 1986, pp. 16-92. 
des cubanas era también de esperarse: la ira incontenida y vituperios contra la toma de posición de los nuevos regímenes de Europa central.

Pero el efecto más grave del cambio de los regímenes en Europa central sobre la economía cubana se observa en el colapso de las relaciones comerciales entre esas dos partes. Según G. Ca. brera, subdirector del diario Granma: "Cualquier país que pierde de la noche a la mañana el $\mathbf{8 5} \%$ de sus relaciones económicas inernacionales se hunde." 17 El funcionario cubano se refirió al brusco descenso de los intercambios de Cuba con Europa central y oriental, debido tanto a los factores políticos (cambio de orientación ideológico-política de los países centroeuropeos) como a las consideraciones de indole estrictamente financiera (el cálculo con base en monedas convertibles y a precios del mercado internacional).

La posición de la URSS vis-à-vis de Cuba es muy compleja. La Unión Soviética no puede abandonar simple y llanamente a un aliado muy fiel durante más de 30 años, tal como se desprende de las declaraciones oficiales soviéticas. ${ }^{18}$ Por otro lado, la grave crisis económica que incluso se agudiza día con día no permite a los soviéticos cumplir con todos los requerimientos de la directiva cubana. Todo parece indicar que la parte soviética no puede

17 El Economista, 24 de junio de 1991 , p. 5.

18 Declaración de A. Ermakov, el jefe de la sección de América Latina en la cancillería soviética, quien dijo: "El gobierno soviético no está dispuesto a interrumpir al asistencia a Cuba, como lo inform6 previamente la agencia Interfax". Excélsior, 7 de julio de 1991. acatar los compromisos contraídos de exportación e importación con la isla caribeña por la falta de buques, medios de almacenamiento y una deficiente coordinación entre diferentes instancias del comercio exterior ${ }^{19} \mathrm{~A}$ todo ello habría que añadir las presiones norteamericanas de suspender cualquier asistencia soviética a Cuba a cambio de una ayuda occidental para convertir el sistema estatizado de la economía de la URSS en uno de mercado. 20

En su resultado, la economía de Cuba enfrenta el desafio de subsistencia, de cambiar las prioridades y de movilizar todos los recursos. En boca del ministro de Relaciones Exteriores de Cuba, Sánchez Parodi:

Lo que necesitamos es una reorientación, un ajuste muy duro en términos de reducción del consumo; en la construcción de vivienda -entre otras cosas-; pero necesario, debido a la situación que enfrentamos ahora en nuestras relaciones económicas internacionales, por los cambios en Europa del este y la URSS. ${ }^{21}$

Por esas razones fue puesto en marcha desde finales de 1990 un programa de recortes y austeridad denominado "el periodo especial".

Con respecto a la situación interna

19 "Aguda situación de desabasto vive Cuba", Excélsior, 4 julio 1991, pp. 4, 11.

20 Véase nota 18. El mismo funcionario admitió tal presión en las siguientes palabras: "Tal intención no es un secreto, pues ha sido evidenciada en documentos del senado estadunidense $y$ en deciaraciones de altas personalidades de este país."

${ }^{21}$ El Economista, 24 de junio de 1991. 
en los países centroeuropeos, se observa una marcada división. Por un lado se desprenden países como Po. lonia, las repúblicas Checa y Eslovaca, Hungría, que provocan una desestatización de las economías nacionales y que se están vinculando en. tre sí y con la Comunidad Europea, to cual augura que en el plazo de 10 a 15 años esos países pueden lograr su incorporación al Mercado Común Europeo y ostentar el estatus de países "desarrollados". ${ }^{22} \mathrm{Ob}$ viamente, tal perspectiva sólo puede alcanzarse bajo premisas optimistas, es decir descartando la aparición de los factores irruptivos, al estilo de la violencia social, la ingobernabilidad, etcétera.

Por otro lado, países como Bulgaria, Rumania, Albania y Yugoslavia parecen deslizarse al nivel de los países tercermundistas con todas las lacras conocidas: pobreza extrema, hambre, insalubridad pública, violencia en todas sus formas, cuestionamiento de la elite política, marginación en el comercio internacional, etcétera. ${ }^{23}$

Igualmente en este subgrupo se trata más bien de una tendencia, reversible por cierto, pero cargada de signos ominosos y de primeras manifestaciones en este sentido.

Pero la mayor incógnita la presenta,

22 "Modernizar países del este puede tomar una década", según el estudio realizado por encargo del Banco Mundial, Excélsior, 2 de mayo de 1991 , pp. 3, 4 .

23 R. G. Kaiser, "Occidente, frío ante la revolución de Europa del este; los europeos no ven la región como una oportunidad", The Wasbington Post, traducido en Excélsior, 1 de junio de 1991, pp. 3 y 5. sin lugar a dudas, la propia URSS. Particularmente en los dos últimos años se ha agravado la crisis económica; amén de la falta de una política económica coherente, la pugna entre las tendencias centralizadoras y separatistas, la disputa por el poder en todos los niveles. Todo el mundo está de acuerdo en que la Unión Soviética sigue enfrentando el creciente déficit presupuestal, la escasez de productos a pesar del considerable aumento de precios, la depreciación galopante de su moneda y la disminución drástica de su comercio exterior, incluyendo al principal producto de exportación: el petróleo. ${ }^{24}$ No se necesita insistir en que la URSS, por su tamaño, número de habitantes y el poderío militar que aún conserva, es la pieza clave en la escena internacional y un desequilibrio serio en sus componentes económicos o políticos tendría repercusiones incalculables para el resto de los países. De ahí la gran preocupación mundial y también la impotencia de no saber ni poder ayudar.

Ahora bien, ¿qué perspectivas se pueden esbozar a partir del hundimiento del socialismo real en Europa central para los países del tercer mundo? El terreno de la prognosis es muy resbaladizo y semejante al de las conjeturas; para evitar aquéllas propongo adoptar ciertos escenarios; es décir, opciones bastante abiertas que puedan consumarse bajo determinadas condiciones.

Así, el temor ampliamente divul-

${ }^{24}$ Luis de Cervantes, "Peligro de guerra civil", Excélsior, 18 de abril de 1991, pp. 1 y 10. 
gado de que el cambio de los regímenes en Europa del este afectará el flujo de la ayuda internacional de los países altamente desarrollados, principalmente a los del tercer mundo, ya que los primeros canalizarán todos los recursos disponibles a la construcción de la economía de mercado y a la consolidación de las estructuras democráticas en los países de Europa central, es un argumento que nos parece al menos exagerado. Vemos que la ayuda internacional se distribuye cada vez más, vía organismos internacionales, y éstos se rigen por consideraciones globales y requerimientos de diferentes órdenes de prioridades divididas continentalmente y/o por zonas. Su reparto depende también de la voz de los países tercermundistas y de la región dada. En los casi dos años transcurridos desde el desmoronamiento de los regímenes comunistas no hubo un deslizamiento espectacular en el flujo de la ayuda internacional.

Sin embargo, hay que anotar una mutación en el otorgamiento de préstamos gubernamentales, a los bancos internacionales y comerciales. Esa mutación ya se observó con toda evidencia a partir del inicio de la década de los 80 y se tradujo en condiciones muy duras: saneamiento de las finanzas públicas, control de salarios, apertura arancelaria y la disminución del sector estatal, etcétera. Todo ello parece indicar que se mantendrá dicha política crediticia en el futuro inme. diato, tomando en cuenta el giro prevaleciente de las políticas neoliberales a escala mundial. El caso de Europa central sólo reforzó esta tendencia, ya sea en el seguimiento de las políti- cas económicas en esa zona, ya sea en la proliferación indiscriminada de las posturas neoliberales en los medios de comunicación y las universidades. ${ }^{25}$

Por otra parte, cabe albergar la esperanza de que el ingreso de los países centro europeos, o al menos algunos de ellos, a la economía del mercado mundial tendrá consecuencias benéficas para el incremento del comercio internacional y para todos los países interesados en participar en él. En opinión del líder de Ghana, $\mathrm{J}$. Rawlings, el recorte en las relaciones económicas entre Europa central y África puede revertirse en el futuro no muy lejano: "Si las economías de Europa oriental empiezan a funcionar de nuevo, lo que significará la apertura para los productos africanos. En todo caso, preferimos el comercio a la ayuda." 26 No es aislada esta opinión de que el comercio, sobre todo si es justo y equitativo, es mucho más dinamizador $y$, por consiguiente, más benéfico que una ayuda, una dádiva.

En la esfera política quedan abiertos diferentes escenarios. El fin del bipolarismo y de la confrontación esteoeste, característica de la guerra fría, puede transformarse en época de unipolarismo, a saber: la hegemonía incuestionada de Estados Unidos. Pero, por otro lado, una vez desaparecido el pretexto de intervencionismo norteamericano que ha sido "la infiltración soviética" en la zona de influencia considerada como suya, es legítimo esperar el respeto a las decisiones soberanas de cada uno de los países

\footnotetext{
25 Patula, "Transformaciones" (mimeo).

26 Rawlings, "Suivons", 1990, p. 7.
} 
de la región. Tal perspectiva es realizable bajo la condición de contar con formas apropiadas de impedir cualquier intervención extranjera, por ejemplo: al vigorizar a la ONU, a las organizaciones internacionales de tipo continental y regional, al movilizar la opinión pública, etcétera. El caso de Panamá en 1989 puso en evidencia la falta de esos contrapesos. Siguiendo el razonamiento de Carlos Andrés Pérez, el presidente de Venezuela, la intervención norteamericana en Panamá en diciembre de 1989 fue precedida por una "intervención negativa" de los países latinoamericanos. El mandatario venezolano dijo literalmente: " $\mathrm{La}$ iniervención estadunidense fue producto de la intervención negativa de América Latina: la no intervención latinoamericana se convirtió en una intervención en el caso panameño."27

A título de conclusiones, es aún prematuro constatar el surgimiento del nuevo orden internacional. La desaparición paulatina de las fronteras en cuanto a la integración económica regional no siempre conlleva a la desaparición de las fronteras políticas. Con respecto a las relaciones entre Europa central y el tercer mundo, en el futuro mediato, éstas se asemejan a una hoja en blanco. ¿Cómo y quién la llenará?, esto dependerá de muchos factores aún imprevisibles por el momento. iOjalá que lo hagan los pueblos y los

27 Entrevista concedida a D. Julius, Excélsior, 12 de julio de 1991, p. 10. gobiernos electos democráticamente y que sea en provecho mutuo!

\section{BIBLIOGRAFIA}

-Albright, D. E., "The USSR and the third world in the 1980's", Problems of Communism, marzo-junio 1989.

-Dueñas Pulido, A., "Visión histórica de la política soviética hacia el tercer mundo", Foro Internacional, núm. 112, 1989.

-Gorbachov, M., Perestroika. Nuevas ideas para mi país y el mundo, Diana, México, 1990.

-Hough, J. F., The struggle for the third world; soviet debates and american options, Brookings Institution, Washington, D.C., 1986.

-Katz, M. N., "The Soviet Union and the third world", Current History, octubre 1986.

-Navarro Wolf, A., "Peligro de la democracia", La Jornada Semanal, 7 julio 1991.

-Pabon, C., "Implications of changes in eastern Europe and the USSR for the third world: five views", Peace \& Democracy News, otoño 1990.

-Patula, Jan, "Ontología del socialismo real", Anuario de Humanidades de la UAMIztapalapa, Signos (en prensa).

, "Transformaciones de las relaciones de propiedad en Europa del este" (mimeo).

-Rawlings, J., "Ne suivons aucun modèle", Le Nouvel Afrique Asie, núm. 10, 1990.

-Staar, R., Soviet foreign policy after détente, Hoover Institution Press, Stanford, 1986.

-Valkanier, K., "Treinta y cinco años de cambios en las relaciones económicas entre la Unión Soviética y el tercer mundo", Foro Internacional, núm. 112, 1988. 